\section{Effectiveness of iron repletion in the diet for the optic nerve development of anaemic rats}

AS DeMaman 1,2,3, P Melo33, JM Homem', MA Tavares ${ }^{2,3}$ and J-J Lachat ${ }^{1}$

\section{Abstract}

Purpose To compare the process of myelination in the developing optic nerve (ON) of anaemic rats with the subsequent recovery after being fed an iron-recovery diet. Methods In this study, the morphometrical parameters in the $\mathrm{ON}$ were assessed by electron microscopy in Wistar rats that were on an iron-deficient diet for 32 days or for 21 days followed by 10 days on an iron-recovery diet. Qualitative and quantitative analyses were performed using representative electron ultramicrographs. Data were analysed by one-way analysis of variance (ANOVA). When differences were detected, comparisons were made using Tukey's post hoc test $(P<0.05$ was considered to be significant).

Results Qualitative analysis of the ONs in anaemic and recovered animals showed a higher rate of deformed axons and increased lamellar separation in the myelin sheath when compared with the respective control group. The $\mathrm{ON}$ of the anaemic group showed a reduced mean density of myelinated fibres when compared with the control group. The fibre area ratio, axon area ratio, and myelin area ratio of large axons/small axons in the ONs of the control group showed the highest values for the myelin areas, axon areas, and total fibre areas. The control group showed a significantly higher myelin sheath thickness when compared with the anaemic and recovered groups.

Conclusions Our data indicate that iron is necessary for maintenance of the $\mathrm{ON}$ cell structure, and that morphological damage from iron deficiency is not easily reverted by iron repletion.

Eye (2010) 24, 901-908; doi:10.1038/eye.2009.205; published online 14 August 2009
Keywords: iron repletion; optic nerve; rat; development; iron-deficiency anaemia

\section{Introduction}

Anaemia is a widespread public health problem and iron deficiency is the most common cause of anaemia. ${ }^{1,2}$ For half a billion women in developing regions, anaemia is a lifelong burden, one that affects most of their infants and young children as well. ${ }^{3-5}$ The demand for iron increases during growth periods, and consequently iron deficiency during pregnancy in humans is frequently associated with prematurity and perinatal mortality. ${ }^{6}$ Iron deficiency is associated with an increase in complications in pregnant women and with poorer foetal growth and survival. ${ }^{7}$ Recent evidence relates poor iron status during pregnancy with increased risk of chronic disease later in life. ${ }^{8}$

Iron is an essential trace element, and, given its role in oxygen transport and the low levels of iron availability in the diets of a large proportion of the global population, it is assumed that iron deficiency is one of the major contributing factors to the global burden of anaemia. Iron deficiency is considered one of the ten leading global risk factors in terms of its attributable disease burden. ${ }^{4}$ There is an interconnectedness of iron-dependent changes in neurochemistry, ${ }^{9}$ neurometabolism, and neuroanatomy during development, inducing changes in sensory/motor, cognitive/language, and social/emotion domains in iron-deficient people. ${ }^{10}$ Iron is required for normal myelination and pathway transmission in the sensory systems may be affected by early iron deficiency. Moreover, iron deficiency in humans is reportedly associated with a decrease in auditory and visually evoked potentials attributed to hypomyelination. ${ }^{11}$ Magnetic

\section{${ }^{1}$ Laboratório de} Neuroanatomia, Faculdade de Medicina de Ribeirão Preto, Departamento de Cirurgia e Anatomia, Universidade de São Paulo, Ribeirão Preto, SP, Brasil

${ }^{2}$ Faculdade de Medicina, Instituto de Anatomia J. A. Pires da Silva, Universidade do Porto, Porto, Portugal

${ }^{3}$ Instituto de Biologia Molecular e Celular, Universidade do Porto, Porto, Portugal

Correspondence: P Melo, Instituto de Biologia Molecular e Celular, Universidade do Porto, Rua Campo Alegre 823, Porto 4150 180, Portugal Tel: 35191966 7101; Fax: 351226099157.

E-mail: pmelo@

ibmc.up.pt

Received: 2 December 2008 Accepted in revised form: 30 June 2009 Published online: 14 August 2009 
resonance imaging in human infants also indicated that altered iron status is associated with hypomyelination. ${ }^{12}$

The role of iron in myelination and oligodendrocyte biology has been studied for several decades., ${ }^{2,13-15}$ Specific iron-requiring enzymes involved in maintaining a high rate of metabolic and biosynthetic activity, such as glucose-6phosphate dehydrogenase, dioxygenase, succinic dehydrogenase, and NADH dehydrogenase, as well as the cytochrome oxidase system, are all elevated in

oligodendrocytes relative to other cells in the brain. ${ }^{16}$ Iron is an essential component of stearoyl-CoA desaturase. ${ }^{17}$ This enzyme complex catalyses the synthesis of oleate, which is the precursor for nervonic acid synthesis. ${ }^{18}$ As nervonic acid is a major component of cerebroside, a characteristic myelin lipid, it has been attributed an important role in myelinogenesis. ${ }^{15,19,20}$ A direct effect of iron deficiency on myelin has been shown, which includes a decrease in lipids ${ }^{13}$ and some proteins. ${ }^{6}$ Furthermore, peak iron uptake into the brain coincides with the onset of myelination. ${ }^{21}$ Iron is involved both directly in myelin production as a required cofactor for cholesterol and lipid biosynthesis and indirectly as its requirement for oxidative metabolism, which occurs in oligodendrocytes at a higher rate than other brain cells. ${ }^{22}$ The presence of transferrin in the CNS appears to be essential for myelination, and all oligodendrocyte progenitors produce and respond to transferrin before myelination; ${ }^{23}$ so, it is likely that the oligodendrocyte progenitor is the most promising cell population to ultimately rescue the myelin-deficient brain. Transferrin availability is essential for oligodendrocyte maturation and function, and oligodendrocytes are most vulnerable to transferrin deficiency during the premyelinating stage. ${ }^{24}$ Therefore, iron deficiency in early life is associated with delayed development as assessed by a number of clinical trials using similar global scales of development; this poor development during infancy persists in most cases after iron therapy has corrected the iron status. If iron deficiency occurs in preschool and older children, the consequences appear reversible with treatment. Dietary iron deficiency can rapidly deplete brain iron concentrations and repletion is able to normalize them..$^{2}$ Disruptions in iron processing, storage, or availability affect both the quantity and quality of myelin. In addition, the myelin composition and quantity are altered even if the iron content of the myelin achieves normal levels. ${ }^{14}$

The visual system is extremely vulnerable to trace elements deficiency. Deficiencies of $\mathrm{Zn}, \mathrm{Cu}, \mathrm{Mn}$, and vitamins $\mathrm{A}, \mathrm{B} 12$, and $\mathrm{E}$ induced degeneration and disappearance of myelin lamellae in the myelinated optic nerve (ON) fibres. ${ }^{25}$ Multideficient diet affected permanently the rat $\mathrm{ON}$ organization and myelination, indicating an impairment of nerve transmission and a probable dysfunction in the visual ability. The percentage of myelinated axons and the myelin area were decreased in malnourished groups. ${ }^{26}$ The $\mathrm{ON}$ is simple, relatively homogeneous, and is a suitable structure to analyse development changes in the visual system after exposure to trace elements deficiency. It is a well-characterized CNS structure that has been used in numerous studies. ${ }^{27,28}$ The visual pathways are vulnerable structures to insults such as deficiency diet, drugs of abuse, and alcohol. ${ }^{29-37}$

In this study, we examined the effect of iron repletion administrated after weaning on the ON development of rats fed with an iron-deficient diet since birth until the postnatal day (PND 21). The quantitative changes analysed in the ON of iron-deficient rats and after iron repletion provides a baseline pattern to the ON damage, which will lead to a better understanding of the ophthalmologic alterations found in children breastfed from anaemic women.

\section{Materials and methods}

\section{Experimental design and diet administration}

Handling and care of animals were performed according to the Brazilian College of animal experimentation (COBEA) regulations and approved by the ethics committee of the São Paulo University in Brazil. The Wistar rats used in this study were bred in the Laboratory of Neuroanatomy of the Department of Surgery and Anatomy, University of São Paulo, Brazil. At the beginning of the experimental period, 2-month-old nulliparous female rats were housed in polyethylene cages $(41 \times 40 \times 17 \mathrm{~cm})$ with stainless steel tops, feeders, and bottle caps, in conditions of constant temperature at $22 \pm 2{ }^{\circ} \mathrm{C}$ and humidity around $60 \%$, with a 12-hour light/ dark cycle. Three dams were used for each treatment (control, anaemic, recovered) giving a total of nine litters for the experiment. The day of birth was designated PND 0. Litters were left undisturbed until PND1 when the pups were weighed and the litters were randomly culled to six male pups. The animals received water and diet with the same caloric content ad libitum. The control group was maintained with $35 \mathrm{mg}$ of iron $/ \mathrm{kg}$ diet throughout the entire experience (PND 0-32); the anaemic group was maintained with $4 \mathrm{mg}$ of iron $/ \mathrm{kg}$ diet throughout the entire experience (PND 0-32), and the recovered group was maintained with $4 \mathrm{mg}$ of iron $/ \mathrm{kg}$ diet during breastfeeding (PND 0-21) and maintained with $35 \mathrm{mg}$ of iron/ $\mathrm{kg}$ diet after weaning (PND 22-32). In all groups, the diet was ingested by the progenitor rat during lactation and by the pups after weaning.

The haemoglobin concentration and haematocrit percentage were measured from $1 \mathrm{ml}$ of blood collected from the pups after anaesthesia on the thirty-second day from all groups. 
All the materials used for housing and animal care, such as glassworks, stainless steels and plastic materials, were washed earlier with nitric acid $30 \%(\mathrm{v} / \mathrm{v})$ solution and rinsed with deionized water, preventing contamination with environmental iron. The composition of the diet, vitamin, and salt mixtures are according to earlier work. ${ }^{37}$

\section{Tissue processing}

At PND 32, each pup was killed by transcardiac perfusion with a buffered saline solution $0.05 \mathrm{M}$ phosphate buffer at $\mathrm{pH} 7.3$ followed by a $2 \%$ paraformaldehyde and $1 \%$ glutaraldehyde fixative in $0.1 \mathrm{M}$ phosphate butter at $\mathrm{pH} 7.3$, under anaesthesia. The volume of the perfusion solution for each animal was $1 \mathrm{ml} / \mathrm{g}$ of body weight.

After perfusion, ONs were rapidly dissected between the optic chiasm and the deflection for the ocular globe. ONs were immersed in the same fixative and rinsed for $2 \mathrm{~h}$ in phosphate buffer. The ONs were then postfixed for $2 \mathrm{~h}$ in $1 \%$ of osmium tetroxide diluted in $0.1 \mathrm{M} \mathrm{PB}, \mathrm{pH}$ 7.3, for $2 \mathrm{~h}$ at $4{ }^{\circ} \mathrm{C}$. Osmicated tissues were dehydrated through an ascending series of acetone and embedded in araldite. ONs were placed in deep coffin moulds and orientated to permit transversal sections of their fibres. The moulds were then placed at $50^{\circ} \mathrm{C}$ overnight. ${ }^{32}$ From each $\mathrm{ON}$, semi-thin sections $(0,5 \mu \mathrm{m}$ thick) were cut perpendicularly to the long axis of the nerve, stained with toluidine blue to be used for light microscopy to verify the quality of the section for transmission electron microscopy. ON ultrathin cross-sections were cut (Reichert Ultracuts Om U3, New York, USA) and picked up on copper grids and subsequently double-stained with uranyl acetate and lead citrate.

\section{Quantitative analysis}

Quantitative studies were performed on six animals (males) per group (PND 32), randomly selected from different litters. A transmission electron microscope (JEOL 100 CX II, Tokyo, Japan) was used to capture ultrathin $\mathrm{ON}$ transverse sections at PND 32. From each $\mathrm{ON}$, eight photomicrographs $(\times 3400)$ at $\times 10200$ final amplification and four photomicrographs $(\times 13000)$ at $\times 39000$ final amplification were obtained.

Photomicrographs were digitalized and further processed in Olympus DP-soft software for Windows (version 3.0, Hamburg, Germany).

The percentage of myelination was determined by counting both the number of unmyelinated fibres and the number of myelinated fibres in three different $64 \mu \mathrm{m}^{2}$ regions in each of the eight photomicrographs $(\times 3400)$ with the final amplification $(\times 10200)$. These different
$64 \mu \mathrm{m}^{2}$ squares were randomly chosen in each photomicrograph, though avoiding areas with glial nuclei. Myelin sizes, axon/myelin ratio, myelinated fibre sizes, delineated by the outer margins of their myelin sheaths, and axon sizes, by the inner circumference of the myelin sheaths, were measured. At least six axons were counted in each photomicrograph and only fibres cut transversely were included in the measurements.

All measurements were performed relying on a proven systematic random sampling ${ }^{38,39}$ and photomicrographs were coded before and analysed blindly to avoid experimental bias.

\section{Statistics}

For comparison among groups of pups, one-way ANOVA was applied. When differences were detected, comparisons were made using Tukey's post hoc test. $P<0.05$ was accepted to be significant (SPSS Statistical Software Programs version 16.0, Chicago, IL, USA).

\section{Results}

The haemoglobin concentration $(4.13 \mathrm{~g}$ per $100 \mathrm{ml}$ ) and the haematocrit percentage $(13.83 \%)$ of the anaemic pups were reduced in comparison with the control group (10.95 g per $100 \mathrm{ml}$ and $37 \%$, respectively). Nevertheless, the iron-rich diet of the recovery group permitted an almost complete restoration of these blood values $(10.55 \mathrm{~g}$ per $100 \mathrm{ml}$ and $35.66 \%$, respectively). So, there was a statistically significant difference of haemoglobin $(P<0.001)$ and haematocrit percentage $(P<0.003)$ in the control and recovery groups in comparison with the anaemic group, but between the control group and the recovery group there was no difference.

Representative electron ultramicrographs of sections taken through the $\mathrm{ON}$ from rats at PND 32 are shown in Figure 1. The ONs in anaemic and recovered animals showed a higher rate of deformed axons and increased lamellar separation in the myelin sheath when compared with the respective control group.

At PND 32, no statistically significant differences were found between groups concerning the total area and the minimum diameter of the cross-section of the rat $\mathrm{ON}$. No differences were found in the total number of myelinated and unmyelinated fibres among control, anaemic, and recovered pups; nevertheless, in Figure 2, the ON of the anaemic group showed a reduced mean density of myelinated fibres when compared with the control group $(P=0.038)$. The anaemic group had a reduced percentage of myelinated axons (80.6\%) and a higher percentage of unmyelinated axons (19.4\%) in the ON when compared with the control (86.2 and 13.8\%) and recovered (84.0 and $16.0 \%)$ groups. Although in the recovered group the 

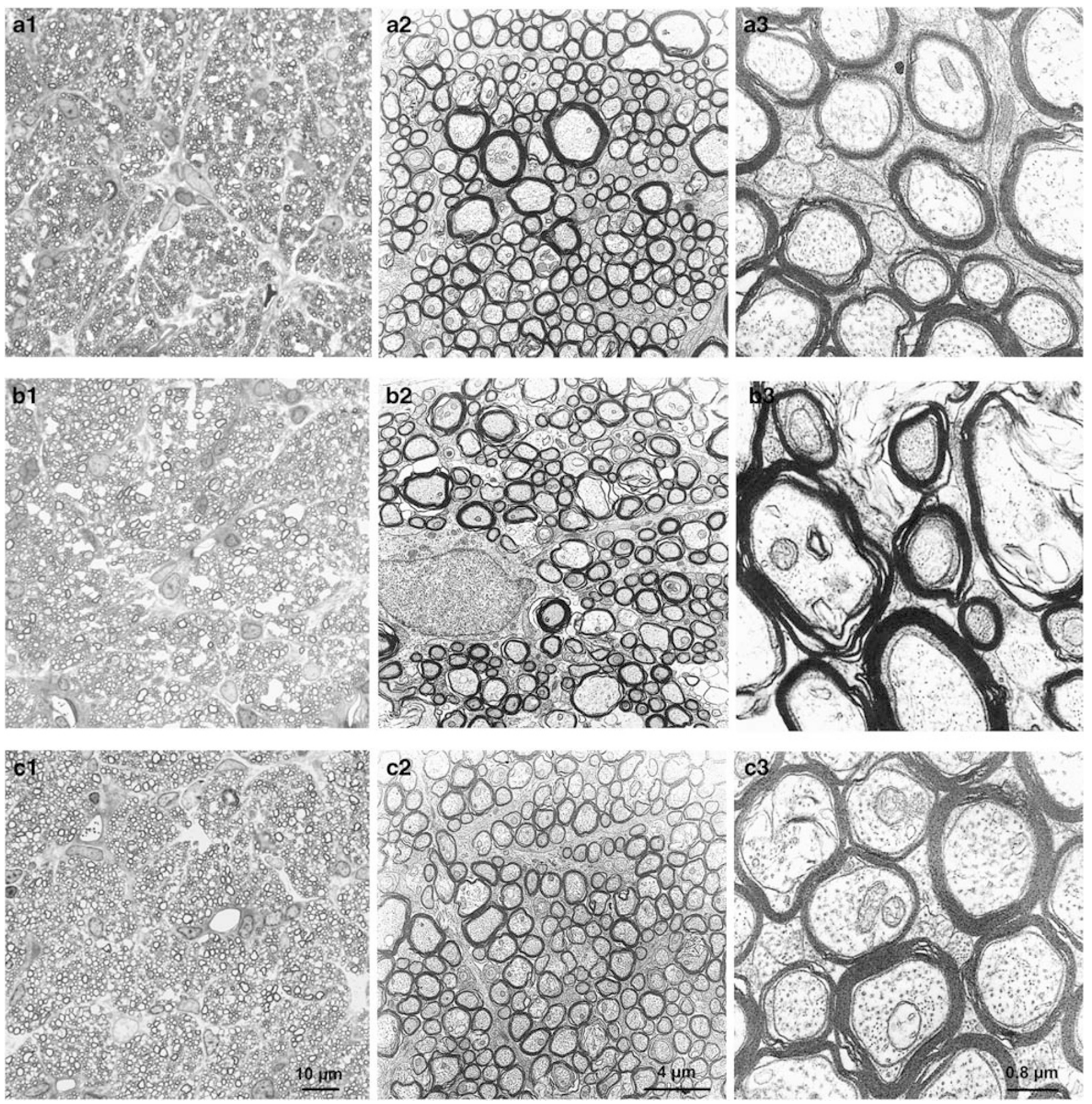

Figure 1 Representative light micrographs of transverse cross-sections of rat optic nerve stained with toluidine blue (a1, b1, c1) at $\times 1250$ magnification. Representative electron micrographs of transverse cross-sections of the rat optic nerve stained with uranil acetate and lead citrate $(\mathrm{a} 2, \mathrm{~b} 2, \mathrm{c} 2)$ at $\times 3400$ magnification; and (a3, b3, c3) at $\times 13000$ magnification. Control (A), anaemic (B), and recovered (C) groups at PND 32. Scale bar $=10 \mu \mathrm{m}$ (left panels), $4 \mu \mathrm{m}$ (middle panels), and $0.8 \mu \mathrm{m}$ (right panels).

percentage of myelinated axons was higher when compared with the anaemic group, it did not reach the levels of the control group. The mean diameter of axons and the mean diameter of myelinated fibres did not significantly differ among the three groups of animals.

The ON axons were divided into two different categories: axons with an area of more than $0.8 \mu \mathrm{m}^{2}$ (large axons) and axons with an area of less than $0.8 \mu \mathrm{m}^{2}$ (small axons). At PND 32, no difference was found in the total number of myelinated axons of both large and small axons among the control, anaemic, and recovered groups. The myelin area of the small axons was statistically higher $(P=0.007)$ in the recovered group $\left(F_{(2,15)}=6.525\right)$ than in the control group (Table 1). The area of large and small axons and the total fibre area of large and small axons did not differ among the three experimental groups. The fibre area ratio, axon area ratio, and myelin area ratio of large axons/small axons in the 
ONs of male rats at PND 32 is represented in Figure 3. The control group obtained the highest myelin areas, axon areas, and total fibre areas. Concerning the large axons, the control group showed a significantly higher myelin sheath thickness $\left(F_{(2,14)}=12.153\right)$ when compared with the anaemic $(P=0.002)$ and recovered $(P=0.003)$ groups. No differences were found among the three groups in the myelin sheath thickness of the small axons (Figure 4).

\section{Discussion}

Qualitative analysis of the ONs in anaemic and recovered animals showed a higher rate of deformed axons and increased lamellar separation in the myelin sheath when compared with the respective control group. The ON of the anaemic group showed a reduced mean density of myelinated fibres when compared with the control group. The fibre area ratio, axon area ratio and myelin area ratio of large axons/small axons in the ONs of the
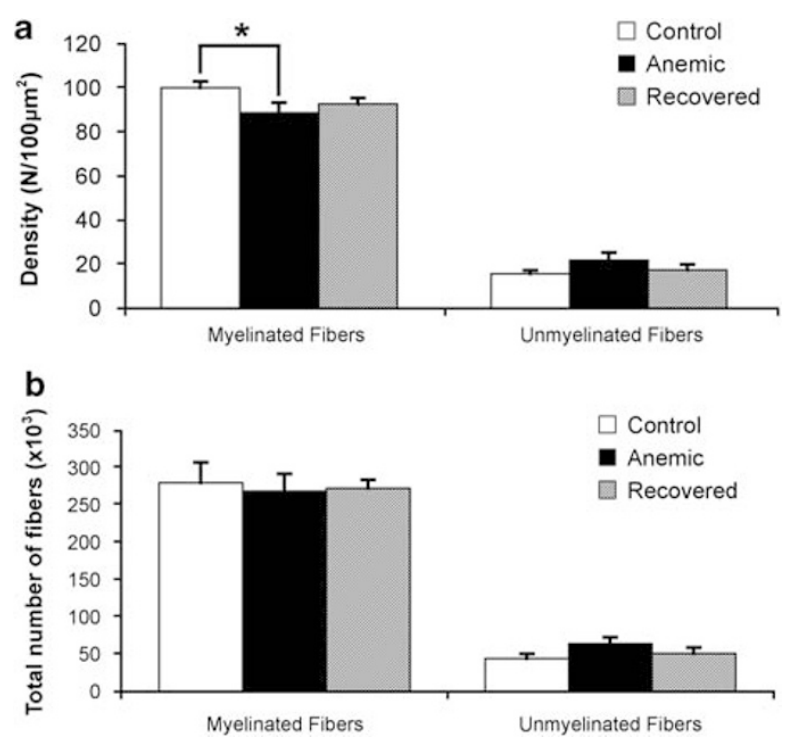

Figure 2 Mean density (a) and total number (b) of myelinated and unmyelinated fibres of the optic nerve in the control, anaemic, and recovered rats at postnatal day 32. Values are means \pm SE for $n=6 ;{ }^{*} P<0.05$. control group obtained the highest value concerning myelin areas, axon areas and total fibre areas. The control group showed a significantly higher myelin sheath thickness when compared with the anaemic and recovered groups. Our data indicate that iron is necessary for maintenance of the ON cell structure, and morphological damage from iron deficiency is not easily reverted by iron repletion.

Optic nerve development starts early in neurogenesis and continues postnatally throughout the maturation of the cell lineages to the end of myelination. ${ }^{40,41}$ Iron deficiency affects the normal myelination and the pathway transmission in the sensory systems. ${ }^{11,12}$ Trace elements deficiency, undernourishment, and exposure to drugs of abuse or alcohol induced ultrastructural changes in the $\mathrm{ON}$, cornea, and retina. ${ }^{25,26,29,31-35,42-53}$

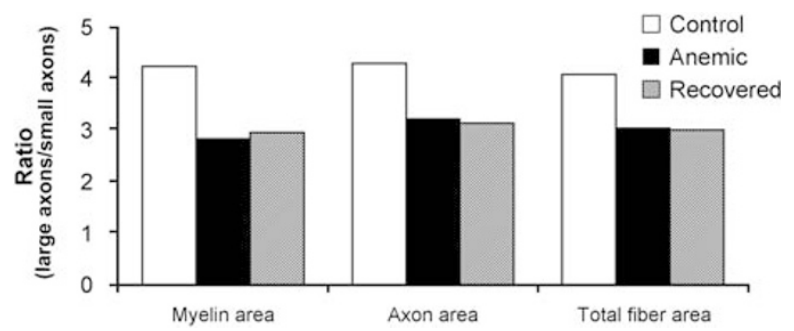

Figure 3 Fibre area ratio, axon area ratio, and myelin area ratio of large axons $\left(>0.8 \mu \mathrm{m}^{2}\right) /$ small axons $\left(<0.8 \mu \mathrm{m}^{2}\right)$ of the optic nerve in the control, anaemic, and recovered rats at postnatal day 32 for $n=6$.

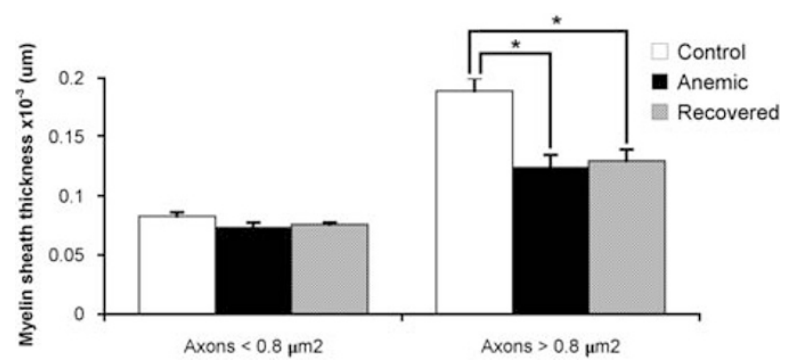

Figure 4 Myelin sheath thickness of both large axons $\left(>0.8 \mu \mathrm{m}^{2}\right)$ and small axons $\left(<0.8 \mu \mathrm{m}^{2}\right)$ of the optic nerve in the control, anaemic, and recovered rats at postnatal day 32 . Values are means \pm SE for $n=6 ;{ }^{*} P<0.05$.

Table 1 Summary of the quantitative data of the optic nerve fibres in the control, anaemic, and recovered rats at PND 32

\begin{tabular}{|c|c|c|c|c|c|c|}
\hline & \multicolumn{2}{|c|}{ Fibre area } & \multicolumn{2}{|c|}{ Axon area } & \multicolumn{2}{|c|}{ Myelin area } \\
\hline & $\begin{array}{c}\text { Axons } \\
<0.8 \mu m^{2}\end{array}$ & $\begin{array}{c}\text { Axons } \\
>0.8 \mu m^{2}\end{array}$ & $\begin{array}{c}\text { Axons } \\
<0.8 \mu m^{2}\end{array}$ & $\begin{array}{c}\text { Axons } \\
>0.8 \mu m^{2}\end{array}$ & $\begin{array}{c}\text { Axons } \\
<0.8 \mu m^{2}\end{array}$ & $\begin{array}{c}\text { Axons } \\
>0.8 \mu m^{2}\end{array}$ \\
\hline Control & $0.53 \pm 0.039$ & $2.17 \pm 0.365$ & $0.33 \pm 0.027$ & $1.42 \pm 0.200$ & $0.20 \pm 0.012^{*}$ & $0.85 \pm 0.156$ \\
\hline Anaemic & $0.55 \pm 0.029$ & $1.68 \pm 0.242$ & $0.32 \pm 0.020$ & $1.05 \pm 0.105$ & $0.23 \pm 0.011$ & $0.64 \pm 0.073$ \\
\hline Recovered & $0.60 \pm 0.014$ & $1.81 \pm 0.112$ & $0.34 \pm 0.012$ & $1.07 \pm 0.072$ & $0.25 \pm 0.005^{*}$ & $0.75 \pm 0.060$ \\
\hline
\end{tabular}

Data represent mean fibre area, mean axon area, and mean myelin area of the rat optic nerve fibres and are expressed as mean \pm SE for $n=6$; ${ }^{*}<0.05$. PND, postnatal day. 
Gong and Amemiya ${ }^{44}$ showed ultrastructural disarrangement in the retina of manganese-deficient rats. A reduction of the percentage of myelinated axons and the myelin area was found in the $\mathrm{ON}$ of undernourished rats. ${ }^{26} \mathrm{Zn}$-deficient rats presented myelin destruction and glial cells proliferation in the $\mathrm{ON}$ and change of the quantity of trace elements and vitamin $C$ in the cornea. ${ }^{47,50}$ The $\mathrm{ON}$ axons of methamphetamine-treated females had a reduction of MBP protein expression and a reduction of the myelin thickness. ${ }^{33}$ Alcohol and methamphetamine intoxication induced abnormalities in the myelination and severe delays in the development of the retina and $\mathrm{ON}$, in addition to causing ultrastructural alterations. ${ }^{33,52,54}$ The exposure to a relatively high dose of ethanol for a short period during the rats' early postnatal life markedly influenced the development, myelination, and total numbers of $\mathrm{ON}$ axons. ${ }^{29}$

In this work, we evaluated the structural impairment of the rat $\mathrm{ON}$ resulting from postnatal iron-deficient diet ( $4 \mathrm{mg} \mathrm{Fe} / \mathrm{kg}$ diet) and the effect of iron repletion (35 mg $\mathrm{Fe} / \mathrm{kg}$ diet) after weaning. The experimental design effectively produced maternal iron-deficient anaemia, which indicated low iron status of their offspring. ${ }^{37}$

A similar experimental regime has been used elsewhere. 9,55,56

Dietary iron deficiency results in a wide variety of structural and physiological defects ${ }^{22,56,57}$ and a decrease in lipids and proteins on myelin. ${ }^{6,13}$ Iron-deficient children were reported to have longer auditory brainstem response and visual-evoked potential latencies attributed to hypomyelination. ${ }^{11}$ The neural functioning and behavioural consequences on brain iron deficits are not limited to infants. ${ }^{6,13}$

There are growing evidences that iron deficiency in early development affected brain myelination, ${ }^{14,22,58}$ and some of them include a general decrease of its content and a differential composition of myelin. ${ }^{14,57}$ The high levels of transferrin and iron in the after-birth period suggest that iron is extremely important to nervous system development for myelinization and development. Importantly, transferrin expression by oligodendrocytes is closely associated with the amount of myelin. ${ }^{57}$ The importance of iron in myelin production has been shown by studies showing that the decreased availability of iron in the diet is associated with hypomyelination. The timing of iron delivery to oligodendrocytes during development is also important because hypomyelination and the associated neurological sequelae persist long after the systemic iron deficiency has been corrected. ${ }^{59}$ We were able to conclude that ONs from iron deficiency diet-treated animals at PND 32 have a higher percentage of unmyelinated axons, and that iron repletion after weaning was not sufficient to revert this situation. This finding occurred together with a reduction in the mean density of myelinated fibres of the anaemic group. A peculiar aspect of this investigation is that the myelin area of the small axons was higher in the recovered group when compared with the control group. Although there are not sufficient data to explain this result, the oedema in the axons and its myelin shields can be the support to clear this finding. Harris et al. ${ }^{29}$ showed that the proportion of axons that were myelinated at PND 30 was also lower in the high dose ethanol-treated animals than in the other groups. Melo et al. ${ }^{31}$ showed that the percentage of myelinated axons in the $\mathrm{ON}$ did not differ between methamphetamine-treated animals and their respective age-matched controls.

Myelin formation starts late in development after neuronal proliferation and migration. ${ }^{60}$ Insults, such as trace elements deficiency, malnutrition, or even altered functioning of the thyroid gland, can influence the myelination process in a persistent manner. ${ }^{25,44-46,53,61}$ Myelinogenesis continues until adolescence in both rodents $^{61}$ and humans. ${ }^{62,63}$ It is known that myelinogenesis in the rat ON starts around PND 7, and between the second and fifth weeks of the postnatal period that a rapid increase in myelination is observed. ${ }^{64}$ In this study, the anaemic pups received $4 \mathrm{mg}$ of iron $/ \mathrm{kg}$ diet until PND 32 and showed a reduction in the myelin sheath thickness in axons with an area of more than $0.8 \mu \mathrm{m}^{2}$ when compared with the control group. The iron repletion was not efficient, as half of the anaemic animals that received $4 \mathrm{mg}$ of iron $/ \mathrm{kg}$ diet until the weaning day and $35 \mathrm{mg}$ of iron/ $\mathrm{kg}$ diet from PND 21 to PND 32 maintained the myelin sheath thickness similar to that of the anaemic group.

The mechanisms underlying the hypomyelination induced by iron deficiency are not known with certainty. The predominant cell type containing iron in the young brain is the white matter oligodendrocytes, with a rapid accumulation of iron in these cells at the onset of myelination. ${ }^{56,65}$ The densities of oligodendrocytes, astrocytes, blood vessels, and damaged myelinated fibres of the rat $\mathrm{ON}$ were influenced by iron deficiency during the first few weeks of life. ${ }^{37}$ The percentage of myelin occupancy for axons of methamphetamine-treated animals was significantly affected, and the average myelin area was reduced. ${ }^{31}$

Further investigations are needed to explain the detailed role of iron to the visual system. The ratio of large axons/small axons showed that the control group obtained the highest myelin areas, axon areas, and total fibre areas. These results provide evidence that exposure to an iron-deficient diet during active periods of development induces damage to the $\mathrm{ON}$ that may influence the normal functioning of the visual system.

Taken together, the results from this study provide support for the need to ensure adequate iron nutrition 
during early development to prevent chronic iron deficiency in humans, which generates irreversible consequences to the normal development of the nervous system.

\section{Acknowledgements}

The authors thank Maria Tereza Maglia for valuable technical assistance. AS DeMaman was recipient of a fellowship from the CAPES. P Melo was recipient of a fellowship from Fundação para a Ciência e Tecnologia (BPD/26477/2006). This work was supported by Financiamento Plurianual do IBMC.

\section{References}

1 Rodgers A, Vaughan P, Prentice T, Edejer TT-T, Evans D, Lowe J. The World Health Report 2002: Reducing Risks, Promoting Health Life. Geneva: World Health Organization, 2002.

2 Beard JL, Connor JR. Iron status and neural functioning. Annu Rev Nutr 2003; 23: 41-58.

3 United Nations AS. Second Report on the World Nutrition Situation - Volume I: Global and Regional Results. Geneva: ACC/SCN, 1992.

4 Kraemer K, Zimmermann MB. Nutritional Anemia. Switzerland: SIGHT AND LIFE, 2007.

5 Yager JY, Hartfield DS. Neurologic manifestations of iron deficiency in childhood. Pediatr Neurol 2002; 27(2): 85-92.

6 Beard J. Iron deficiency alters brain development and functioning. J Nutr 2003; 133(5 Suppl 1): 1468S-1472S.

7 WHO/UNICEF/UNU. Report of a WHO/UNICEF/UNU Consultation of Indicators and Strategies for Iron Deficiency Anaemia Programmes. Geneva: WHO, 1993.

8 Barker D. Mothers, babies and disease in later life. London: BMJ Publishing House, 1994.

9 Erikson KM, Jones BC, Beard JL. Iron deficiency alters dopamine transporter functioning in rat striatum. J Nutr 2000; 130(11): 2831-2837.

10 Lozoff B, Georgieff MK. Iron deficiency and brain development. Semin Pediatr Neurol 2006; 13(3): 158-165.

11 Algarin C, Peirano P, Garrido M, Pizarro F, Lozoff B. Iron deficiency anemia in infancy: long-lasting effects on auditory and visual system functioning. Pediatr Res 2003; 53(2): 217-223.

12 Deregnier RA, Nelson CA, Thomas KM, Wewerka S, Georgieff MK. Neurophysiologic evaluation of auditory recognition memory in healthy newborn infants and infants of diabetic mothers. J Pediatr 2000; 137(6): 777-784.

13 Larkin EC, Rao GA. Importance of Fetal and Neonatal Iron: Adequancy for Normal Development of Central Nervous System. London: Springer-Verlag, 1990.

14 Ortiz E, Pasquini JM, Thompson K, Felt B, Butkus G, Beard J et al. Effect of manipulation of iron storage, transport, or availability on myelin composition and brain iron content in three different animal models. J Neurosci Res 2004; 77(5): 681-689.

15 Yu GS, Steinkirchner TM, Rao GA, Larkin EC. Effect of prenatal iron deficiency on myelination in rat pups. Am J Pathol 1986; 125(3): 620-624.
16 Cammer W. Oligodendrocyte associated enzymes. In: Norton WT (ed), Oligodendroglia. Plenum Press: New York, 1984.

17 Strittmatter P, Spatz L, Corcoran D, Rogers MJ, Setlow B, Redline R. Purification and properties of rat liver microsomal stearyl coenzyme A desaturase. Proc Natl Acad Sci USA 1974; 71(11): 4565-4569.

18 Fewster ME, Ihrig T, Mead JF. Biosynthesis of long chain fatty acids by oligodendroglia isolated from bovine white matter. J Neurochem 1975; 25(3): 207-213.

19 Baumann NA, Jacque CM, Pollet SA, Harpin ML. Fatty acid and lipid composition of the brain of a myelin deficient mutant, the "quaking" mouse. Eur J Biochem 1968; 4(3): 340-344.

20 Joseph KC, Druse MJ, Newell LR, Hogan EL. Fatty acid composition of cerebrosides, sulphatides and ceramides in murine leucodystrophy: the quaking mutant. J Neurochem 1972; 19(2): 307-312.

21 Crowe A, Morgan EH. Iron and transferrin uptake by brain and cerebrospinal fluid in the rat. Brain Res 1992; 592(1-2): 8-16.

22 Connor JR, Menzies SL. Relationship of iron to oligodendrocytes and myelination. Glia 1996; 17(2): 83-93.

23 Espinosa de los Monteros A, de Vellis J. Myelin basic protein and transferrin characterize different subpopulations of oligodendrocytes in rat primary glial cultures. J Neurosci Res 1988; 21(2-4): 181-187.

24 Espinosa de los Monteros A, Kumar S, Zhao P, Huang CJ, Nazarian R, Pan T et al. Transferrin is an essential factor for myelination. Neurochem Res 1999; 24(2): 235-248.

25 Amemiya T. The eye and nutrition. Nippon Ganka Gakkai Zasshi 1999; 103(12): 829-850.

26 Almeida MF, Silveira AC, Guedes RC, Hokoc JN, Martinez AM. Quantitative ultrastructural evidence of myelin malformation in optic nerves of rats submitted to a multideficient diet. Nutr Neurosci 2005; 8(2): 91-99.

27 Crespo D, O'Leary DD, Cowan WM. Changes in the numbers of optic nerve fibers during late prenatal and postnatal development in the albino rat. Brain Res 1985; 351(1): 129-134.

28 Tennekoon GI, Cohen SR, Price DL, McKhann GM. Myelinogenesis in optic nerve. A morphological, autoradiographic, and biochemical analysis. J Cell Biol 1977; 72(3): 604-616.

29 Harris SJ, Wilce P, Bedi KS. Exposure of rats to a high but not low dose of ethanol during early postnatal life increases the rate of loss of optic nerve axons and decreases the rate of myelination. J Anat 2000; 197(Part 3): 477-485.

30 Pinazo-Duran MD, Renau-Piqueras J, Guerri C, Stromland $\mathrm{K}$. Optic nerve hypoplasia in fetal alcohol syndrome: an update. Eur J Ophthalmol 1997; 7(3): 262-270.

31 Melo P, Pinazo-Duran MD, Salgado-Borges J, Tavares MA. Correlation of axon size and myelin occupancy in rats prenatally exposed to methamphetamine. Brain Res 2008; 1222: 61-68.

32 Silva-Araújo A, Salgado-Borges J, Tavares MA. Morphological changes in the optic nerve after chronic exposure of neonatal rats to cocaine and amphetamine. Ophthalmic Res 1991; 23(6): 295-302.

33 Melo P, Moreno VZ, Vazquez SP, Pinazo-Duran MD, Tavares MA. Myelination changes in the rat optic nerve after prenatal exposure to methamphetamine. Brain Res 2006; 1106(1): 21-29. 
34 Silva-Araújo A, Salgado-Borges J, Cardoso V, Silva MC, Castro-Correia J, Tavares MA. Changes in the retinal ganglion cell layer and optic nerve of rats exposed neonatally to cocaine. Exp Eye Res 1993; 56(2): 199-206.

35 Silva-Araújo A, Tavares MA. Development of the eye after gestational exposure to cocaine. Vascular disruption in the retina of rats and humans. Ann N Y Acad Sci 1996; 801: 274-288.

36 Summavielle T, Silva-Araújo A, Silva MC, Tavares MA. Effects of neonatal exposure to cocaine in the development of the neurotransmitters retinal systems: an immunocytochemical and neurochemical study. Ann $\mathrm{N} Y$ Acad Sci 2000; 914: 418-430.

37 DeMaman AS, Homem JM, Lachat JJ. Early iron deficiency produces persistent damage to visual tracts in Wistar rats. Nutr Neurosci 2008; 11(6): 283-289.

38 Parson SH, Dhillon B, Findlater GS, Kaufman MH. Optic nerve hypoplasia in the fetal alcohol syndrome: a mouse model. J Anat 1995; 186(2): 313-320.

39 Parson SH, Sotijra NM. Loss of myelinated axons is specific to the central nervous system in a mouse model of the fetal alcohol syndrome. J Anat 1995; 187(3): 739-748.

40 Hirose G, Bass NH. Maturation of oligodendroglia and myelinogenesis in rat optic nerve: a quantitative histochemical study. J Comp Neurol 1973; 152(2): 201-209.

41 Takayama S, Yamamoto M, Hashimoto K, Itoh H. Immunohistochemical study on the developing optic nerves in human embryos and fetuses. Brain Dev 1991; 13(5): 307-312.

42 Endo K, Itoh N, Maehara S, Shinozaki A, Imagawa T, Uehara $\mathrm{M}$ et al. Functional disorder of the retina in manganese-deficient Japanese quail revealed by electroretinography using a contact lens electrode with built-in light source. J Vet Med Sci 2008; 70(2): 139-144.

43 Pons S, Zanon-Moreno V, Melo P, Vila V, Gallego-Pinazo R, Pinazo-Duran MD. Optic neuropathy induced by prenatal drug or alcohol exposure. Arch Soc Esp Oftalmol 2007; 82(1): 21-26.

44 Gong H, Amemiya T. Ultrastructure of retina of manganesedeficient rats. Invest Ophthalmol Vis Sci 1996; 37(10): 1967-1974.

45 Gong H, Amemiya T. Optic nerve changes in manganesedeficient rats. Exp Eye Res 1999; 68(3): 313-320.

46 Gong H, Amemiya T. Corneal changes in manganesedeficient rats. Cornea 1999; 18(4): 472-482.

47 Gong H, Amemiya T. Optic nerve changes in zinc-deficient rats. Exp Eye Res 2001; 72(4): 363-369.

48 Gong H, Amemiya T, Takaya K. Retinal changes in magnesium-deficient rats. Exp Eye Res 2001; 72(1): 23-32.

49 Gong H, Takami Y, Amemiya T. Ultrastructure of the optic nerve in magnesium-deficient rats. Ophthalmic Res 2003; 35(2): 84-92.
50 Gong H, Takami Y, Amemiya T, Tozu M, Ohashi Y. Ocular surface in Zn-deficient rats. Ophthalmic Res 2004; 36(3): 129-138.

51 Gong H, Takami Y, Kitaoka T, Amemiya T. Corneal changes in magnesium-deficient rats. Cornea 2003; 22(5): 448-456.

52 Melo P, Rodrigues LG, Silva MC, Tavares MA. Effects of prenatal exposure to methamphetamine on the development of the rat retina. Ann N Y Acad Sci 2006; 1074: 590-603.

53 Wiggins RC, Fuller GN, Brizzee L, Bissel AC, Samorajski T. Myelination of the rat optic nerve during postnatal undernourishment and recovery: a morphometric analysis. Brain Res 1984; 308(2): 263-272.

54 Pinazo-Duran MD, Renau-Piqueras J, Guerri C. Developmental changes in the optic nerve related to ethanol consumption in pregnant rats: analysis of the ethanolexposed optic nerve. Teratology 1993; 48: 305-322.

55 Allen LH. Anemia and iron deficiency: effects on pregnancy outcome. Am J Clin Nutr 2000; 71(5 Suppl): 1280S-1284S.

56 Wu LL, Zhang L, Shao J, Qin YF, Yang RW, Zhao ZY. Effect of perinatal iron deficiency on myelination and associated behaviors in rat pups. Behav Brain Res 2008; 188(2): 263-270.

57 Beard JL, Wiesinger JA, Connor JR. Pre- and postweaning iron deficiency alters myelination in Sprague-Dawley rats. Dev Neurosci 2003; 25(5): 308-315.

58 de los Monteros AE, Korsak RA, Tran T, Vu D, de Vellis J, Edmond J. Dietary iron and the integrity of the developing rat brain: a study with the artificially-reared rat pup. Cell Mol Biol (Noisy-le-grand) 2000; 46(3): 501-515.

59 Todorich B, Pasquini J, Garcia C, Paez P, Connor J. Oligodendrocytes and myelination: the role of iron. Glia 2009; 57(5): 467-478.

60 Miller RH, Ono K. Morphological analysis of the early stages of oligodendrocyte development in the vertebrate central nervous system. Microsc Res Tech 1998; 41(5): 441-453.

61 Wiggins RC. Myelin development and nutritional insufficiency. Brain Res 1982; 257(2): 151-175.

62 Hunter SF, Leavitt JA, Rodriguez M. Direct observation of myelination in vivo in the mature human central nervous system. A model for the behaviour of oligodendrocyte progenitors and their progeny. Brain 1997; 120(Part 11): 2071-2082.

63 Paus T, Zijdenbos A, Worsley K, Collins DL, Blumenthal J, Giedd JN et al. Structural maturation of neural pathways in children and adolescents: in vivo study. Science 1999; 283(5409): 1908-1911.

64 Dangata YY, Kaufman MH. Myelinogenesis in the optic nerve of $(\mathrm{C} 57 \mathrm{BL} \times \mathrm{CBA}) \mathrm{F} 1$ hybrid mice: a morphometric analysis. Eur J Morphol 1997; 35(1): 3-17.

65 Connor JR. Iron regulation in the brain at the cell and molecular level. Adv Exp Med Biol 1994; 356: 229-238. 